\title{
Significato clinico della filamina A nei pazienti acromegalici e sua associazione con il profilo recettoriale per la somatostatina e per la dopamina
}

\author{
Salvatore Cannavò ${ }^{1}$
}

Pubblicato online: 11 aprile 2019

(c) Springer Nature Switzerland AG 2019

\section{Commento a:}

Clinical significance of filamin $A$ in patients with acromegaly and its association with somatostatin and dopamine receptor profiles.

M.C. Coelho, M.L. Vasquez, L.E. Wildemberg, M.C. Vázquez-Borrego, L. Bitana, A.H. Camacho, D. Silva, L.L. Ogino, N. Ventura, R. Sánchez-Sánchez, L. Chimelli, L. Kasuki, R.M. Luque, M.R. Gadelha. Sci Rep (2019) 9:1122

Recenti studi hanno dimostrato che la filamina A, una proteina del citoscheletro, svolge un ruolo rilevante nella espressione dei recettori sst2 per la somatostatina nei tumori ipofisari GH secernenti [1]. Questa proteina, codificata da un gene situato nel cromosoma $X$, esercita una funzione cruciale per le modificazioni conformazionali della membrana cellulare. La filamina A lega infatti numerose proteine transmembrana, incluse le proteine accoppiate al recettore G, e le àncora all'actina del citoscheletro, favorendo l'interazione proteina-proteina. Alcuni studi in vitro hanno dimostrato che una ridotta espressione di filamina A sembrerebbe conferire resistenza agli analoghi della somatostatina nei somatotropinomi [1], e che l'espressione di filamina A correla con quella dei recettori per la dopamina nei prolattinomi [2].

Nello studio pubblicato da Coelho e collaboratori è stato valutato non solo il rapporto fra filamina $\mathrm{A}$ ed espressione dei recettori sst2 e sst5 per la somatostatina e dei recettori D2 per la dopamina in un consistente gruppo di soma- totropinomi, ma anche la relazione con la risposta in vivo agli analoghi della somatostatina e con l'invasività del tumore. A tal fine, l'espressione di filamina A e dei sottotipi recettoriali è stata studiata mediante approccio molecolare e immunoistochimico in 96 tumori, la cui invasività è stata valutata mediante la classificazione di Knosp-Steiner. I risultati dello studio hanno dimostrato che l'espressione di filamina A nei somatotropinomi era positivamente correlata con l'espressione di sst5 e di D2, mentre la correlazione con sst2 era significativa solo nei pazienti responsivi agli analoghi della somatostatina. Nessuna associazione è stata individuata fra filamina A e invasione del tumore. Pertanto, in base ai risultati di questo studio si deve concludere che il ruolo della filamina A nei meccanismi di responsività agli analoghi della somatostatina di prima e seconda linea e ai dopamino-agonisti resta ancora da definire attraverso ulteriori studi.

\section{Bibliografia}

1. Peverelli E, Giardino E, Treppiedi D et al (2014) Filamin A (FLNA) plays an essential role in somatostatin receptor 2 (SST2) signaling and stabilization after agonist stimulation in human and rat somatotroph tumor cells. Endocrinology 155:2932-2941

2. Peverelli E, Mantovani G, Vitali E et al (2012) Filamin-A is essential for dopamine $\mathrm{d} 2$ receptor expression and signaling in tumorous lactotrophs. J Clin Endocrinol Metab 97:967-977
S. Cannavò

cannavos@unime.it

1 Dipartimento di Patologia Umana dell'Adulto e dell'Età Evolutiva G. Barresi, Università di Messina, Messina, Italia 